\title{
Em busca de uma Semiosfera Organizacional: textos diversos, sistemas convergentes
}

\author{
Toward an Organizational Semiosphere: various texts, convergent systems
}

\author{
En busca de una semiosfera de la organización: varios textos, sistemas \\ convergentes
}

\author{
Gislene Feiten Haubrich \\ Ernani Cesar de Freitas ${ }^{2}$
}

\begin{abstract}
Resumo
O estudo visa refletir sobre as noções de missão, de visão e de valores na perspectiva da Semiótica da Cultura, além de identificar e analisar similaridades/diferenças entre elementos prescritivos da cultura organizacional disponíveis em portais de empresas do ramo varejista, a partir dos sistemas modelizantes acionados pelos textos selecionados. Adota-se o ponto de vista da Semiótica Russa para análise de textos teóricos e empíricos, conforme Lotman $(1979,1982,1996)$ e Machado $(2003,2010)$. A constituição dos corpora se dá a partir de empresas ranqueadas pelo relatório do IBEVAR, publicado em 2015, no segmento de Moda e Esportes. Como principal evidência, destaca-se a multiplicidade de sistemas modelizantes envolvidos na produção dos textos organizacionais, o que salienta as múltiplas possibilidades de leitura do cenário organizacional mediante o acionamento de conceitos relativos à Semiótica da Cultura.
\end{abstract}

\begin{tabular}{|c|c|}
\hline \multirow{3}{*}{ 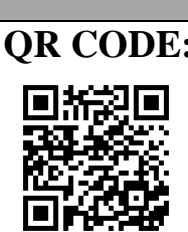 } & Acesse este artigo online \\
\hline & $\begin{array}{l}\text { Website: } \\
\text { http://www.revistas.ufg.br/index.php/ci }\end{array}$ \\
\hline & $\begin{array}{l}\text { DOI: } \\
\text { http://dx.doi.org/10.5216/ci.v20i2.44567 }\end{array}$ \\
\hline
\end{tabular}

Palavras-chave: Sistemas Modelizantes. Elementos Prescritivos. Varejo. Cultura Organizacional.

\section{Abstract}

The study aims to reflect on the notions about mission, vision and values in the perspective of the Semiotics of Culture. In addition, seeks to identify and analyze similarities / differences between prescriptive elements of the organizational culture available in portals of retail companies, from the modeling systems activated by the selected texts. It adopts the Russian Semiotics point of view to understand the theoretical and empirical texts, according to Lotman $(1979,1982$, 1996) and Machado (2003, 2010). The constitution of corpora is based on companies ranked by the IBEVAR report, published in 2015, specifically in the Fashion and Sports segment. The main evidence is the multiplicity of modeling systems involved in the production of organizational texts, which highlights the multiple possibilities of reading the organizational scenario through the activation of concepts related to the Semiotics of Culture.

Keywords: Modeling System. Prescriptive Elements. Retail. Organizational Culture.

\section{Resumen}

\footnotetext{
${ }^{1}$ Doutoranda e mestre em Processos e Manifestações Culturais (Feevale), Especialista em Comunicação Estratégica e Branding (UMayor e Feevale) e graduada em Comunicação Social. E-mail: gisleneh@gmail.com

${ }^{2}$ Doutor em Letras (PUCRS), com pós-doutorado em Linguística Aplicada e Estudos da Linguagem (PUCSP/LAEL). Professor permanente do Mestrado em Processos e Manifestações Culturais (Feevale). E-mail: ernanic@feevale.br
}

Comun. \& Inf., Goiânia, GO, v. 20, n. 2, p. 75-94, jul./out. 2017 
El estudio tiene como objetivo reflexionar sobre la misión, la visión y los valores desde la perspectiva de la semiótica de la cultura e identificar y analizar las similitudes / diferencias entre los elementos prescriptivos de la cultura organizacional que son disponibles en portales de empresas, desde los sistemas modelizantes impulsados por los textos seleccionados. Se adopta el punto de vista del análisis semiótico ruso a los textos empíricos y teóricos como Lotman $(1979,1982,1996)$ y Machado (2003, 2010). La constitución del corpus se produce a partir de empresas ranqueadas por lo informe IBEVAR, publicado en 2015, en el segmento de la moda y los deportes. Como prueba principal, se disse que hay una multitud de sistemas de modelización que participan en la producción de textos de las organizaciones, que pone de relieve las múltiples posibilidades de la lectura del entorno de la organización a través de conceptos de accionamiento para la semiótica de la cultura.

Palabras clave: Sistemas Modelizantes. Elementos Prescriptivos. Comercio. Cultura de la Organización.

\section{NO TRANSGREDIR DAS FRONTEIRAS, A POSSIBILIDADE DE CONSTITUIÇÃO DE UMA SEMIOSFERA}

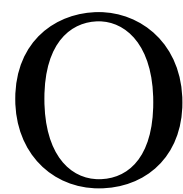

s estudos do campo da Administração, principalmente aqueles que se dedicam às temáticas de gestão, têm como pressuposto o planejamento estratégico para a fundamentação organizacional. Planejamento implica a análise de informações emergentes do contexto na qual está inserida (ou se deseja inserir) a organização, a fim de que a tomada de decisão seja acertada mediante os objetivos para ela estabelecidos. Entre as diferentes seções que compõem o plano estratégico, destaca-se a definição de elementos orientadores da conduta organizacional, os quais são prescritos pelos gestores envolvidos no processo de planejamento ou, dependendo do porte e da profissionalização da gestão, pelo dono da empresa e com apoio de consultores. Tais elementos são como uma síntese de toda a carga simbólica que se deseja imprimir à organização, a fim de que possa impregnar a percepção dos significados acessados por funcionários, clientes e outros públicos.

Missão, visão e valores referem-se às escolhas discursivas explícitas de uma organização para impelir seu interlocutor de sentidos. Mesmo que possam ser interpretados como uma simplificação do universo organizacional, a relevância da existência desses elementos é inquestionável, visto que eles se edificam como pontos de partida para aqueles que pleiteiam a oferta de um novo negócio ao mercado consumidor. O efeito simbólico produzido por essas diretrizes chega a ser definido como identidade corporativa, conforme se pode depreender da perspectiva de Peter Drucker, autor clássico da Administração, por exemplo. Nesse sentido, este estudo inscreve-se em uma conjuntura teórica que visa refletir sobre a produção discursiva organizacional e a intencionalidade imbricada em seus textos, nas 
(inter)conexões entre eles e no modo como produzem uma esfera de significados, cujo propósito é nortear a ação dos diferentes sujeitos que coabitam e interagem nas organizações.

Para tanto, agrega-se à reflexão a visão de mundo da Escola Semiótica da Cultura, ou Semiótica Russa, desenvolvida essencialmente por pesquisadores no eixo Tártu-Moscou, como Vladímir Toporov, Borís Uspiénski, Viatcheslav Ivánov, Eleazar Meletínski e Serguei Nekliúdov, entre outros, liderados por Iúri Lotman. Conforme Lotman (1996, p .52), trata-se da "disciplina que examina a interação de sistemas semióticos diversamente estruturados". Salienta-se que o entendimento construído por essa perspectiva tem como pensamento fundador a inter-relação entre cultura e natureza. Conforme retoma Machado (2010, p. 158), "ao posicionar a ecologia semiótica no âmbito da cultura, Kull realinha as bases teóricas fundadoras do pensamento semiótico da cultura, desenvolvido no eixo Tártu-Moscou nos anos 50-60 do século passado, quando estudiosos de diferentes áreas do conhecimento se dispuseram a pensar sobre as transformações da informação no confronto entre natureza e cultura.".

Com base nesses apontamentos elementares, justifica-se a argumentação pretendida por esse artigo com base no diálogo que se pode estabelecer entre as perspectivas da Semiótica da Cultura e dos estudos organizacionais, sustentada pela noção de sistemas modelizantes, que "são considerados modelos que explicam o mundo" (LOTMAN, 1996, p.169). Acredita-se que esse olhar seja profícuo, pois permite a reflexão da prática gerencial expressa pela escolha das informações na formação dos elementos prescritivos. Nesse caso, tais elementos são percebidos como manifestação dos textos que compõem a semiosfera delimitada por um arranjo cultural específico. Com o estudo, explora-se o potencial de interpretação dos textos no entrecruzar das fronteiras da projeção enunciativa dos chamados "gurus" da Administração em livros acadêmicos, best-sellers, revistas, internet ou outros canais de comunicação e, também, em textos culturais que permeiam as relações de consumo e de trabalho.

$\mathrm{O}$ arcabouço teórico-metodológico acionado neste escopo conduz às problemáticas permeadas por este estudo: como se dá a inter-relação entre os sistemas modelizantes acionados em textos que revelam as estruturas da semiosfera organizacional? Quais são as similaridades/diferenças entre elementos prescritivos da cultura organizacional de empresas brasileiras do ramo varejista, no segmento de Moda e Esportes? Assume-se a hipótese de que, embora haja diferenças nos discursos em análise, elas concentram-se, especialmente, na missão da organização. Por outro lado, supõe-se que acerca da visão e dos valores, tais 
enunciados expressem significados semelhantes. Nesse caso, a articulação entre similaridades e diferenças evidencia sistemas modelizantes de escopos diversos a fim de ordenar as interações de sentido daí provenientes e ampliar as possibilidades de significação no espaço da semiosfera. Diante disso, a principal contribuição do estudo está na possibilidade de descrição de possíveis vínculos de significados acionados nos textos enquanto projeção de sistemas modelizantes de uma semiosfera organizacional.

Como objetivos da pesquisa estabelecem-se: refletir sobre as noções de missão, visão e valores na perspectiva da semiótica da cultura; analisar e identificar similaridades/diferenças entre elementos prescritivos da cultura organizacional disponíveis em portais de empresas do ramo varejista, a partir dos sistemas modelizantes acionados pelos textos. Para tanto, produzse uma breve apresentação/contextualização das noções de missão, de visão e de valores na teoria estratégica da Administração articulada às noções de sistemas modelizantes, fronteiras, semiosfera e texto sob o ponto de vista da Semiótica da Cultura.

Para atender às expectativas do estudo, estabelece-se como objeto empírico o discurso prescritivo divulgado nos portais de organizações varejistas do segmento de Moda e Esportes. A seleção das empresas incluídas como fontes na coleta de dados deu-se a partir do relatório divulgado pelo Instituto Brasileiro de Executivos de Varejo \& Mercado de Consumo IBEVAR - em 2015, no ranking eficiência. O artigo subdivide-se em três partes, além dos apontamentos introdutórios: 1) articulação conceitual; 2) textos empíricos e suas conjecturas; e 3) o fechamento das ideias-chave apresentadas.

\section{SEMIÓTICA E ADMINISTRAÇÃO: TEXTOS E SISTEMAS NA PRODUÇÃO DA SEMIOSFERA ORGANIZACIONAL}

A Semiótica da Cultura se constitui como lente para observar e depreender a realidade. O que a difere de outras abordagens semióticas é o processo, visto que busca estudar a cultura a partir dos textos por ela produzidos, por meio de categorias basilares. Trata-se de uma inversão, pois os pensadores dessa escola " [...] procuravam entender o papel da linguagem na cultura" (MACHADO, 2003, p. 26). A cultura, para Lotman e Uspenski (1981), é indutora de estruturalidade e ancorada no conjunto de linguagens heterogêneas que a compõem. Nesse caso, a linguagem passa a assumir uma noção diferente, pois está vinculada, principalmente, com o processo comunicativo. Conforme Lotman (1982, p. 17), "todo sistema que serve para fins de comunicação entre dois ou numerosos indivíduos pode ser definido como linguagem". Segundo esse autor, a arte, por exemplo, estabelece-se como uma linguagem, pois ordena 
diferentes signos (ou informações) de um modo particular a fim de delimitar um sistema de comunicação.

Assim, na perspectiva da Semiótica da Cultura, todas as linguagens são concebidas por dois sistemas de modelização: 1) o primário, que é a língua (conjunto de palavras e regras), e 2) o secundário, que são as estruturas de comunicação ou os múltiplos modos de organização dos diferentes signos/informações que coabitam no universo simbólico. Abre-se a brecha para uma correlação inicial dentro dos limites propostos para este estudo. Desse modo, tal qual a Arte pode ser percebida como linguagem, investe-se o olhar à Administração. Enquanto proposta teórica, ela procura viabilizar um diálogo entre os diferentes indivíduos que interagem na produção de seus textos: empresas, patrões, trabalhadores, mercado, etc. Interessa ressaltar, ainda, que, vista como linguagem, a Administração é depreendida a partir de sistemas modelizantes diversos, reconhecidos pelas estruturas expressas por seus textos. Feita essa conexão inicial, pode-se avançar na trama prevista.

A concepção da Arte como linguagem, para Lotman (1982), pressupõe uma categorização do seu produto principal, a obra de arte, que, nesse escopo semiótico, é tratada como texto, ou conjunto organizado de informações. A centralidade atribuída ao conceito de texto é relativa à complexidade de sua explicação. Os semioticistas russos procuram romper com a tradição linguística que, para eles, trata o texto de modo elementar. Lotman (1996) assevera que o texto contempla uma dupla codificação: 1) da linguagem natural (língua na cultura); 2) da linguagem expressa por sistemas comunicativos. Nas palavras desse autor, o texto é "um complexo dispositivo que guarda variados códigos, capaz de transformar as mensagens recebidas e gerar novas mensagens" (LOTMAN, 1996, p. 56). Em outra obra, Lotman (1982) afirma que o entendimento da noção de texto pressupõe a conjunção de três elementos: 1) expressão, que infere na relação entre o que é interno e externo no sistema; 2) delimitação, ou seja, que trata de um enquadramento específico; e 3) caráter estrutural, visto que apresenta uma organização interna.

Em suma, texto se refere a uma unidade de informação no sistema da cultura. Por meio da soma de informações, instituem-se os textos que, ao cruzarem suas "fronteiras" de significados, entrelaçam-se e possibilitam a atualização permanente de sentidos e saberes, além de estimular a formação de novos códigos e textos que somam na produção da "semiosfera". Se é que assim se pode dizer, o texto é o catalizador de sentidos em uma cultura. Desse modo, interessa retomar a conexão que este estudo propõe. Se a Administração se estabelece como linguagem, em decorrência, diversos são os textos fundamentados a partir 


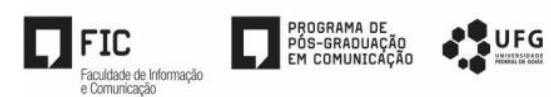

dela, como as diferentes teorias, as ações das organizações, os posicionamentos dos gestores, etc. A evolução dos eventos relacionados ao modo de gestão empresarial é impelida pelo trânsito de informações permanentemente organizado na produção de novos textos.

Evidenciados esses vínculos, compreende-se o movimento de atualização contextual decorrente dos textos. Salientam-se os dois termos em destaque no enunciado anterior que complementam a lente russa para o estudo da relação entre linguagem e cultura: semiosfera e fronteiras. O vínculo entre eles se dá pelo objeto de estudo da Semiótica da cultura, os sistemas modelizantes, que são "as manifestações, práticas ou processos culturais cuja organização depende da transferência de modelos estruturais, tais como aqueles sob os quais se constrói a linguagem natural" (MACHADO, 2003, p. 49). A semiosfera é o "grande sistema", o espaço onde ocorrem os processos comunicativos a partir da condução dos diferentes sistemas modelizantes (LOTMAN, 1996). O que garante o permanente trânsito de informações que atualizam a organicidade dos textos são as fronteiras. O caráter delimitado da semiosfera pressupõe a existência de mecanismos que garantam movimento dos diversos sentidos que são tensionados a partir dos textos. A fronteira cumpre esse papel, pois "é a soma dos tradutores < filtros> bilíngues por meio dos quais se traduz uma outra linguagem para além da semiosfera dada" (LOTMAN, 1996, p. 12).

Assim, a semiosfera constitui-se de sistemas modelizantes responsáveis pela organização das informações em textos através do permear das fronteiras entre o interior e o exterior de linguagens distintas. Relacionando essas concepções ao estudo em desenvolvimento, depreende-se que a semiosfera organizacional, ou seja, o grande sistema que abarca organizações de um segmento, Moda e Esportes, por exemplo, implica diferentes sistemas modelizantes, como os mercados e os arcabouços teóricos que, estruturados por diferentes textos, se entrecruzam a todo tempo; alteram e atualizam a linguagem designada pela Administração. Percebe-se que é difícil delimitar onde o movimento começa ou termina, pois este não é o interesse dos pesquisadores da Semiótica da Cultura, mas, sim, perceber a vivacidade que permite a evolução cultural ordenada em uma dada semiosfera.

Apresentados os conceitos centrais da reflexão russa, procura-se pô-los em diálogo com os textos selecionados para o estudo das estruturas relativas aos elementos prescritivos da cultura organizacional: missão, visão e valores e posteriormente reconhecer a atuação desses sistemas modelizantes nos textos oriundos das empresas selecionadas. Entretanto, antes de navegar por entre eles, reflete-se sobre o contexto que os abarca, o que implica refletir a margem de diferentes sistemas modelizantes que, em dado momento, cruzam fronteiras e 
口FIC

passam a impactar a organização das informações que instituem uma, aqui chamada, semiosfera organizacional. A Figura 1 representa esse movimento de tradução no entrecruzar das fronteiras.

Figura 1 - Sistemas e Fronteiras: atravessamentos na produção de uma semiosfera organizacional

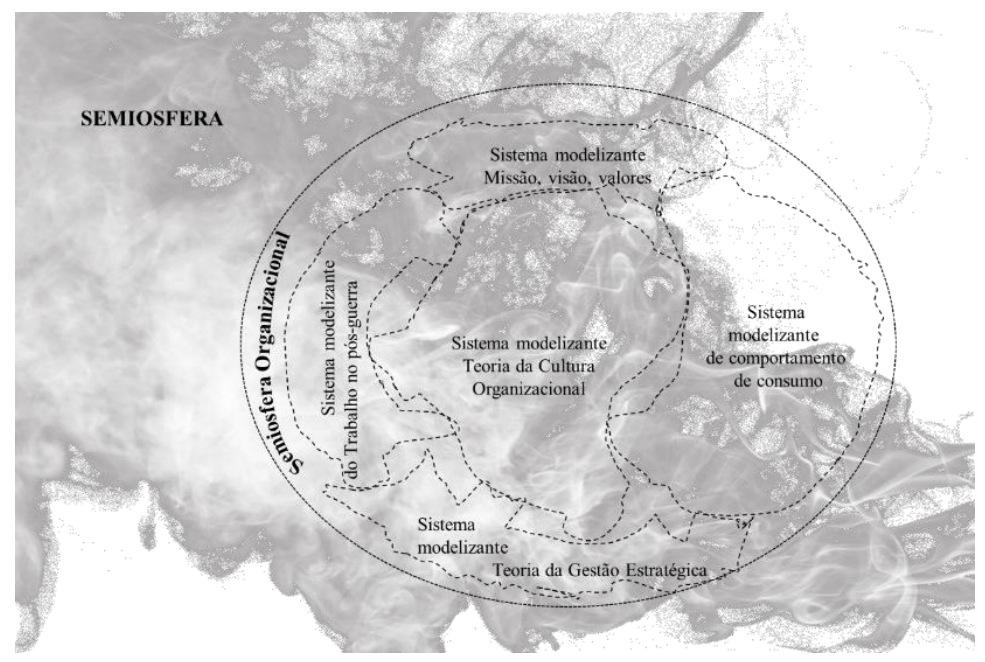

Fonte: elaborada pelos autores

Conforme se percebe na Figura 1, a Semiosfera abarca diferentes sistemas modelizantes, ou seja, informações organizadas em textos e textos organizados em estruturas. A fim de tornar explícita a relação que se procura construir neste estudo, elenca-se um conjunto específico de sistemas que atuam na formação de uma "subsemiosfera", o que se denomina aqui como semiosfera organizacional. Essa escolha se dá por diferentes razões, dentre as quais a oposição que se costuma realizar entre os universos das empresas, território onde o simbólico é posto em segundo plano, e outras manifestações culturais, como a Arte. No entanto, o avanço das perspectivas administrativas tem buscado na sutileza das transgressões dos discursos sobre o trabalho, por exemplo, reconhecer as pistas simbólicas que atuam na transformação de diferentes textos de outros espaços da semiosfera, como da educação ou da família.

A interação entre as diferentes fronteiras dos sistemas modelizantes mencionados na Figura 1 expressa a perspectiva contemporânea investida ao entendimento dos elementos prescritivos em foco. Logo, entender essa interação é processo chave para atender às expectativas da pesquisa. Para tanto, é necessário tomar emprestadas informações do sistema modelizante da Teoria de Gestão Estratégica, que remonta à concepção de planejamento e de estratégia aplicada por vários generais em situações de guerra. Até hoje, escolas de

Comun. \& Inf., Goiânia, GO, v. 20, n. 2, p. 75-94, jul./out. 2017 
Administração e Gestão incluem em suas bibliografias, por exemplo, a obra de Sun Tzu, "A Arte da Guerra". Com o passar dos anos, o diálogo com diferentes eventos da cultura ocidental e seu encontro com o oriente implicaram transformações no processo de planejamento, entre os quais o mais significativo, talvez, seja a Revolução Industrial, suas múltiplas e densas mudanças nos modos de vida dos sujeitos. Nesse período, um dos momentos ápice do sistema capitalista, impera a busca pelo aumento constante na produtividade e elevação do volume de capital.

No contexto norte-americano, fonte de muitas das teorias administrativas trazidas para o Brasil, a virada do Século XX trouxe a ampliação das indústrias e a implementação de meios para aumentar a eficiência produtiva. Diante disso, em 1911, Frederick Taylor elabora a obra seminal da chamada Administração Científica, conhecida também como Organização Científica do Trabalho ou Taylorismo. Racionalização é a palavra-chave da proposta de Taylor, que passa a realizar diferentes estudos, como, por exemplo, dos tempos e movimentos, a hiperespecialização e a padronização, a fim de que os trabalhadores produzissem mais em menos tempo, como partes das engrenagens das máquinas que operavam. Na esteira da produção taylorista, Henry Ford é um dos responsáveis pela popularização do método científico em sua empresa de automóveis. Todavia, dada a vida cíclica do capitalismo, este processo exaustivo de produção implicou o princípio de um de seus declínios, o que foi ratificado por um período extenso de guerras.

O cenário pós-guerra clama pela humanização e os modos de produção orientais passam a ser exemplares para a atualização da teorização da Administração ocidental. Pelbart (2003), nesse mesmo sentido, destaca que a crítica às práticas de gestão do trabalho oriundas de movimentos dos anos 60 serviu de base para o processo revigorante do sistema capitalista, que passou a assimilar elementos como a autonomia, a inalienação e a criatividade, entre outros, em seu modus operandi. Esse "novo espírito do capitalismo" institui o que Pelbart (2003, p. 99) denomina como neomanagement, visto que a partir da inclusão de "[...] temas [que] eram associados a uma crítica radical ao capitalismo, agora são valorizados por si mesmos e postos a trabalhar em favor daquilo que ontem eles criticavam”. Nesse sentido, estabelece-se, conforme esse autor, uma nova normatividade do management contemporâneo.

Hilal (2003, p. 65), na mesma direção de Pelbart, salienta a imbricação do toyotismo às teorias da Administração: “desde o surgimento do Japão como potência industrial dominante, com a sua recuperação após a Segunda Guerra Mundial, os teóricos organizacionais têm ficado cientes do relacionamento entre cultura e gestão”. Nesse ponto, é 
possível perceber a sutileza entre as fronteiras dos sistemas modelizantes estabelecidos pela concepção do trabalho no pós-guerra e a Teoria da Gestão Estratégica, amplamente transformada com a globalização e a ampliação das multinacionais. Pode-se sugerir, inclusive, que o processo de tradução entre esses sistemas teve impactos na produção de novos textos que instituem o sistema da Teoria da Cultura Organizacional. O diálogo entre esses sistemas é transversal ao ponto de não estar explícita a origem do estudo da missão, visão e valores, visto que a primeira os refere como diretrizes organizacionais e a segunda como elementos prescritivos da cultura organizacional. Acredita-se que essa inter-relação manifeste um elemento importante da estrutura que tais diretrizes ou elementos possui.

Na perspectiva do sistema instituído pela Teoria da Gestão Estratégica, as diretrizes organizacionais são "[...] a etapa do processo de administração estratégica que se segue imediatamente à análise do ambiente" (CERTO, et al., 2010, p. 55). A análise do ambiente inclui tanto o interior da organização, mediante suas políticas e procedimentos, quanto seu exterior, por meio dos mapeamentos de concorrência e de públicos. Já no que tange ao sistema da Teoria da Cultura Organizacional, cujos primórdios datam da década de 1980/1990, o enfoque está na relação entre a cultura de um país (ou localidade) e a cultura que se estabelece com as interações entre as pessoas que compõem uma empresa ou instituição (HILAL, 2003). Pode-se indicar uma certa assimilação de mão dupla entre esses dois sistemas, pois alguns pontos de vista compartilham o entendimento de que a inclusão de informações aos textos por elas produzidos servem como base para a mudança comportamental dos ambientes organizacionais onde estão inseridas ${ }^{3}$.

Nesse sentido, cabe trazer a perspectiva de Alves (1997, p. 10) ao asseverar que a "cultura traduz ou reflete as escolhas e preferências que foram desenvolvidas pela liderança (atual e passada) da empresa e que são compartilhadas pelos seus demais membros”. Esse ponto de vista exalta a relevância da produção discursiva prescritiva como elemento-chave para ordenar os textos produzidos pelos trabalhadores no exercício de suas atividades no cotidiano organizacional. Como essas prescrições são resultantes da análise de diversos textos, sob diferentes pontos de vista, pode-se perceber sua congregação mediante a possibilidade de se estabelecer um texto guia à elaboração dos demais. Destaca-se que, nessa ótica, pouca capacidade de transformação é atribuída aos sujeitos, que recebem as orientações e as seguem conforme previsto, o que é improvável, ou mesmo, impossível. Entretanto, este

\footnotetext{
${ }^{3}$ Embora se tenha ciência de propostas interdisciplinares dos estudos organizacionais que admitem a existência de um processo mais complexo na produção simbólica envolvida pelos movimentos de tradução e cruzamentos de fronteiras, neste estudo, o diálogo pretendido impele a inclusão de perspectivas convergentes no entendimento da semiosfera.
}

Comun. \& Inf., Goiânia, GO, v. 20, n. 2, p. 75-94, jul./out. 2017 


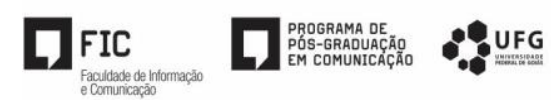

olhar originado do diálogo entre os três sistemas já mencionados, no contexto expresso, avança até certo passo na percepção da humanização da produção laboral.

Alves (1997) aponta a visão e os valores como fatores fundamentais para que se dê um revigoramento cultural. À visão se prevê que "[...] articule uma perspectiva de futuro realista e atrativo, compreensível e compartilhado, e que distinga o que é interesse para a empresa" (ALVES, 1997, p. 31). Nesta obra, esse autor salienta, ainda, exemplos de enunciados que expressam "visões" adequadas à "[...] sua importância como elemento inspirador da conduta empresarial" (ALVES, 1997, p. 57). Por outro lado, Costa (2007, p. 36), ao tratar da Administração Estratégica, afirma que "visão é um modelo mental de um estado ou situação altamente desejável, de uma realidade futura possível para a organização". Desse modo, qualifica-se o enunciado que manifesta a visão como simples, objetivo, abrangente, útil e funcional. Mesmo com divergências no sentido estrito de visão, ambos os autores estão em consonância acerca de determinar estruturas básicas para organizar as informações dispersas nos ambientes organizacionais em prol da produção de um texto organizado e orientador de conduta.

Quanto a reflexão sobre a missão, Costa (2007, p. 36) declara que sua "formulação pretende responder a perguntas como: qual a necessidade básica que a organização pretende suprir?". No mesmo sentido, Certo et al. (2010, p. 56) reiteram que "é uma declaração da razão de ser da organização. [...] Em geral, apresenta informações como os tipos de produto ou serviço que ela oferece, quem são seus clientes e que valores importantes possui”.

Enquanto essas conceituações procuram atribuir um tipo de passo-a-passo para a definição da missão organizacional, Peter Drucker (1993, p. 34), considerado um dos principais teóricos da Administração Contemporânea, assevera que "uma empresa não se define pelo seu nome, estatuto ou produto que faz; ela se define pela sua missão. Somente uma definição clara da missão é razão de existir da organização e torna possíveis, claros e realistas os objetivos da empresa". Pode-se perceber uma lógica estrutural a partir desse enunciado de Drucker: a razão de existir de uma organização advém da organização textual de múltiplas informações esparsas na semiosfera que, uma vez agregadas, expressam a possibilidade de efetivar um novo sistema modelizante ou um novo negócio. Nesse sentido, a missão é classificada enquanto texto basilar aos demais produtos enunciativos de uma organização.

Por fim, os valores "são as noções compartilhadas que as pessoas têm do que é importante e acessível para o grupo a que pertencem. Eles atuam como padrões quanto à 
forma de sentir e de agir, e como roteiros ou critérios para a escolha" (ALVES, 1997, p. 10). Bethlem (1998) salienta que nas organizações os valores estabelecem uma via de mão dupla. Ao mesmo tempo em que se procura determinar quais valores são fundamentais para que sejam atendidos os objetivos da empresa, os indivíduos que nela trabalham também são inebriados por uma carga axiológica acumulada ao longo de diferentes experiências e registros mentais. Nas palavras de Bethlem (1998, p. 56): “a empresa como organismo vivo mantém um processo de equilíbrio e procura um ajustamento das características do ambiente em que opera".

Percebe-se que os significados acionados por Bethlem (1998) convergem com a proposição de Drucker (1973) no que se refere a estruturalidade, pois evidencia o movimento permanente de atualização dos textos organizacionais, no caso os valores, mediante o entrecruzar de fronteiras da semiosfera e a incorporação de novas informações aos sistemas modelizantes que estabelecem a semiosfera organizacional. Assim, diante da costura entre conceitos produzidos pelos semioticistas da escola russa e os autores da Administração, os elementos prescritivos (ou diretrizes organizacionais) passam a ser percebidos como textos produzidos pela cultura, visto que emergem de um contexto coletivo diverso e amplo. A partir dessas conexões teóricas, pode-se prosseguir à investigação no sentido de analisar semelhanças e diferenças entre textos de diferentes sistemas modelizantes expressos por cada empresa incluída nos corpora do estudo.

\section{DA TEORIA À EMPIRIA: TEXTOS ENTRELAÇADOS PELA CULTURA}

A convergência entre a articulação teórica apresentada, o contexto brevemente narrado com a perspectiva da Semiótica Russa e o propósito atribuído ao estudo orienta a sequência da reflexão, cuja base está nas evidências culturais expressas pelos textos em análise e nos sistemas modelizantes articulados na sua produção. Machado (2003) aponta dois pressupostos envolvidos pelo conceito de modelização. O primeiro assevera que transformar sinais em informação é um processo semiótico, pois procede da tradução deles em signos. A segunda conjectura tange "a noção de que nenhum sistema semiótico é dado ao pesquisador, mas, sim, construído". (MACHADO, 2003, p. 50). Diante disso, após a apropriação dos textos que modelizam o olhar que se investe neste estudo, procura-se ampliar as fronteiras da semiosfera resultante do diálogo entre aqueles sistemas modelizantes e se agregam textos oriundos de outra modelização. 
O ponto de vista adotado para a construção dessa perspectiva posiciona missão, visão e valores para além de elementos prescritivos, por vezes dissociados da realidade organizacional. De outro modo, eles são percebidos como textos que manifestam a cultura. Modifica-se a ótica investida ao reconhecimento de tais textos atuantes como referência discursiva dos públicos com os quais a empresa interage e implica a produção de sentidos/atualização de significados relacionados à imagem da organização. Diante disso, estabelecem-se os procedimentos e técnicas aplicadas nesta pesquisa, que se caracteriza como estudo comparativo, mediante a seleção do objeto de análise: discursos prescritivos relativos à missão, visão e valores disponíveis em portais corporativos de empresas brasileiras do ramo varejista, no segmento de Moda e Esportes.

Conforme Bulgacov (1998, p. 56), “[...] o método [comparativo] pode ser definido resumidamente como a comparação sistemática de um grupo determinado de organizações, ou grupos específicos de organizações, com a finalidade de estabelecer relações entre suas variáveis ou categorias analíticas". Nesse sentido, elencam-se as categorias analíticas postas em relação nesta pesquisa: 1) estruturas dos enunciados; 2) modelizações acionadas (conteúdo). A finalidade dos estudos comparativos é também evidenciada por Gil (2008, p. 16), ao ressaltar que procede a "investigação de indivíduos, classes, fenômenos ou fatos, com vistas a ressaltar as diferenças e similaridades entre eles". A viabilidade e proficuidade deste processo metodológico está associado ao propósito deste estudo, identificar similaridades/diferenças entre elementos prescritivos a partir de sistemas modelizantes acionados nos textos relativos à missão, visão e valores que manifestam a semiosfera organizacional que abarca os corpora selecionados.

A seleção dos corpora teve como ponto de partida a escolha de um ramo de negócios, o varejo. A partir disso, a consulta ao Ranking IBEVAR 2015, que aponta as 120 maiores empresas do varejo brasileiro. Conforme esse relatório, "as 120 Maiores Varejistas faturaram aproximadamente R $\$ 424$ bilhões, 12,4\% a mais que na edição 2014” (IBEVAR, 2015, p. 3). A composição do documento se dá a partir de três rankings ${ }^{4}$, dentre os quais, para este estudo, destaca-se o "Ranking Eficiência", cujas empresas em destaque "[...] podem ser consideradas como benchmark na combinação de mão-de-obra e número de lojas para gerar faturamento" (IBEVAR, 2015, p. 5).

\footnotetext{
${ }^{4}$ Os rankings que compõem a edição do relatório são: 1) Ranking por Faturamento Evolução do Setor de Varejo \& Consumo, 2) Ranking de Eficiência, 3) Ranking Imagético.
}

Comun. \& Inf., Goiânia, GO, v. 20, n. 2, p. 75-94, jul./out. 2017 
A opção pelo segmento de Moda e Esportes ${ }^{5}$ deu-se devido ao apelo simbólico que envolve esta divisão do mercado no cotidiano dos sujeitos. Corroboram com essa perspectiva Souza e Leão (2013, p. 624) quando mencionam que "se antes as marcas identificavam o produto por sua utilidade, hoje conferem ao bem de consumo um forte peso simbólico e, por isso mesmo, assumem a condição de verdadeiros canais de autoexpressão através dos quais o consumidor edifica sua identidade".

A fase procedente da definição das empresas, decorreu do acesso aos portais das empresas ${ }^{6}$ para coleta dos dados, etapa que implicou a exclusão da empresa Arezzo \& CO da amostra, pois ela não disponibiliza informações referentes a missão, visão e valores em seu portal corporativo. A Figura 2 apresenta as principais informações de cada empresa que compõe os corpora.

Figura 2 - Breve apresentação dos casos em análise

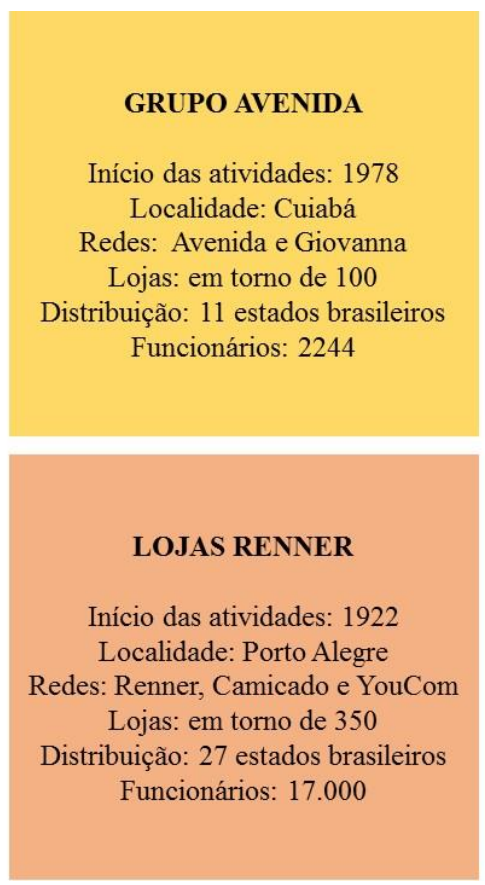

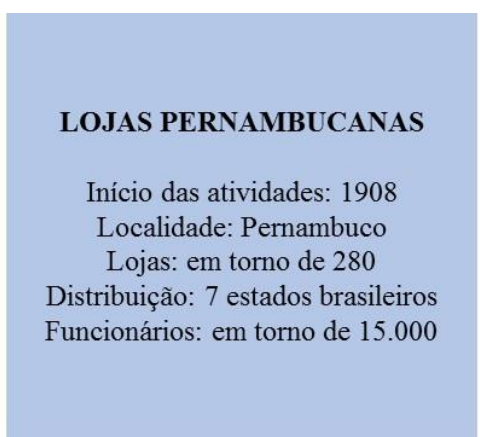

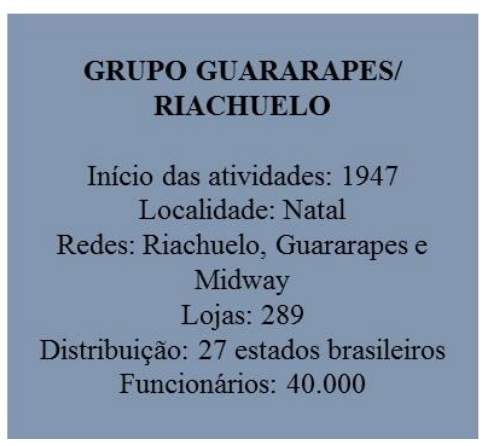

Fonte: elaborada pelos autores

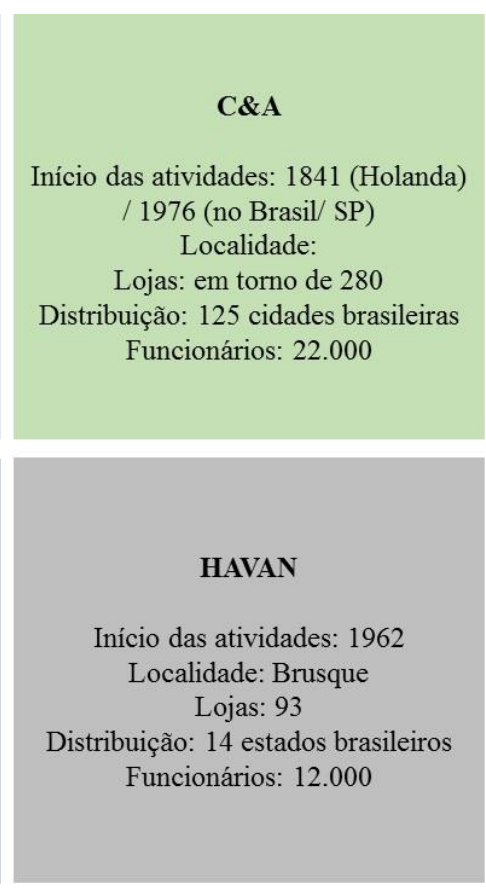

cio das atividades: 1962 dade: Brusqu Funcionários: 12.00

Após a coleta de dados nos portais das empresas selecionadas, bem como de informações breves acerca dos seus históricos, elenca-se como técnica para organização dos

\footnotetext{
${ }^{5}$ A primeira etapa da coleta de dados a partir do relatório teve como ação central a identificação das empresas com destaque no quesito Eficiência. De modo sintético, listam-se as empresas contempladas nesta fase inicial: Casas Pernambucanas, C \& A Modas Ltda, Lojas Renner S.A, Grupo Guararapes, Havan, Arezzo\&CO, Lojas Avenida.
}

${ }^{6}$ A coleta de dados nos portais corporativos foi realizada no dia 03 jul. 2016.

Comun. \& Inf., Goiânia, GO, v. 20, n. 2, p. 75-94, jul./out. 2017 
textos relativos à missão, visão e valores, o Mapa de Associação de Ideias (SPINK, 2005). Trata-se de uma proposta cuja categorização é emergente do objeto empírico analisado, ou seja, após sucessivas leituras, definem-se termos-chave para classificação dos significados acionados pelos textos. Tal definição é decorrente do propósito do estudo associado ao objeto empírico: identificar semelhanças e diferenças entre a divulgação dos textos nos portais das empresas. Salienta-se que, mesmo com buscas exaustivas em sites de pesquisa e outras referências, não foi possível identificar duas informações histórico-contextuais relevantes ao processo analítico: A) empresa pioneira ao adotar as perspectivas estratégica ou cultural no Brasil, conforme delimitação ora expressa; B) empresa pioneira na descrição do item "Quem somos", a partir dos elementos analisados, em portais corporativos. Mesmo diante dessa limitação, prossegue-se o artigo com a apresentação da síntese relativa a cada um dos elementos analisados com base nos corpora de pesquisa.

Considerando as duas categorias analíticas principais, estrutura dos enunciados e modelizações, acerca da missão foram elaboradas três novas categorias: tom, forma e estrutura. Tratam-se de sistemas de modelização secundários que se somam na produção de textos e, desse modo, refletem "uma formulação ritualizada, codificada também mediante alguma linguagem secundária, ou seja, em um texto". (LOTMAN, 1996, p. 53). As três categorias oriundas da organização dos dados em mapas, conforme proposto por Spink (2005) podem relacionar-se, ainda, com os três elementos que constituem o texto na perspectiva de Lotman (1982):

1) Tom vincula-se à expressão: a materialização sistêmica dos signos selecionados na composição do texto converge às modelizações primária, da língua, ou seja, os significados convencionados, e secundária, decorrente dos sentidos que o texto é capaz de produzir mediante sua reorganização permanente e emergente da interpretação extra sistêmica.

2) Forma conecta-se à delimitação: conforme Lotman (1982, p. 72) "o texto possui um significado indivisível”, que assume uma função cultural e delimita significados no tempo e no espaço. Nesse caso, a forma acionada na produção modelizada dos textos relativos à missão, visão e valores das empresas selecionadas demonstra a convenção que perpassa a atualização dos textos, ou seja, sua modelização secundária.

3) Estrutura liga-se ao caráter estrutural mediante a expressão de "uma organização interna que o converte [texto] a um nível sintagmático no todo estrutural” (LOTMAN, 1982, p. 73). Por haver uma estruturalidade incarnada nos textos que se pode vinculá- 
los a uma linguagem ou processo de comunicação, conforme concebido pela Semiótica da Cultura. Na leitura depreendida para este artigo, conforme já apresentado, as Teorias da Administração acionadas são percebidas como linguagem que orienta a produção dos textos culturais/organizacionais.

Quanto ao tom utilizado, transita entre a formalidade e o humor, em alguns casos. Destaca-se o uso da norma culta intercalada com gírias. Da forma de apresentação do texto que enuncia a razão de ser da organização, percebem-se três possibilidades. A exposição em tópicos é utilizada pelo Grupo Avenida, enquanto a Havan e o Grupo Guararapes/Riachuelo expressam a missão por meio de uma frase curta. A forma adotada pela maior parte das empresas (Renner, C\&A e Lojas Pernambucanas) é mediante a divulgação de uma frase longa (igual ou superior a 3 linhas). A exceção da C\&A, que organiza as informações mediante afirmações do que a empresa é, como por exemplo, "Somos uma empresa inovadora, divertida e, acima de tudo, apaixonada pelas pessoas" (C\&A, 2016), as outras cinco empresas utilizam verbos para iniciar os textos, o que evidencia um vínculo entre objetivos e razão de existir.

Quanto à estrutura dos textos, as informações mais mencionadas referem-se a "clientes", no caso de cinco empresas, enquanto quatro aludem a "objetivos/anseios futuros". Outros aspectos mencionados são os produtos/serviços, oferta de qualidade e preço, menção ao lucro, resultado ou legado, valores e outros públicos. A partir dessa caracterização, sugerese que a proposta elencada por Certo et al. (2010), sobre a declaração prestada pelas organizações com base nos produtos/serviços e clientes, é evidenciada pelos textos. Contudo, percebe-se a intervenção de outras modelizações, para além da proposta das teorias ligadas à Administração, visto que a maior parte das empresas aciona o significado do conceito de “objetivos" aplicado à situação fixada pela missão. Nesse sentido, fica evidente que concepções de sistemas modelizantes diversos são incorporados ao universo corporativo, como da Psicologia e da Sociologia, cujo propósito é tornar a organização um indivíduo humanizado e capaz de abarcar e envolver outros indivíduos em prol de um bem comum.

A abordagem dos corpora acerca da visão também teve como ponto de partida as categorias analíticas apresentadas anteriormente. Dessa organização seminal, uma nova subdivisão foi depreendida em duas categorias centrais. A primeira reflete as modelizações utilizadas por quatro empresas que expressam foco no "futuro do negócio no mercado". Nesse caminho, percebe-se que a orientação à produção do texto é a noção de precisão, que responde à demanda metodológica apresentada por textos teóricos. Retoma-se aqueles acionados neste 


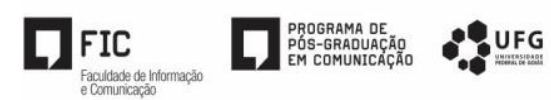

artigo, com base nas proposições de Alves (1997), acerca da visão enquanto uma perspectiva realista de futuro, e de Costa (2007), com base na simplicidade e funcionalidade dos enunciados. Pode-se dizer, então, que a atuação do sistema modelizante da teoria da Administração é evidenciada. Nesse caso, entre os textos produzidos assemelham-se quanto a curta extensão, enquanto um deles, divulgado pelas Lojas Pernambucanas, diferencia-se pelo detalhamento de segmentação do mercado.

A segunda categoria advinda do escopo da visão é estruturada a partir da construção textual de duas empresas, que mostram a intervenção de outros sistemas modelizantes, como, por exemplo, a retórica da perspectiva do Marketing: "encantar a todos" (Lojas Renner) e "construir um legado" (C\&A). Em ambos os casos, os textos se caracterizam pela ambiguidade e, diante disso, valem-se menos dos sistemas modelizantes oriundos das vertentes da cultura organizacional ou da gestão estratégica. De outro modo, reconhece-se o entrecruzar das fronteiras da semiosfera organizacional que envolve as empresas que compõem os corpora. Importa retomar, conforme aponta Machado (2010, p. 69), que "a fronteira define-se como um mecanismo de semiotização capaz de traduzir as mensagens externas em linguagem interna, transformando a informação (não texto) em texto”. Assim, concebe-se que termos como "encantar" e "legado" estão associados a um tipo de mensagem externa, ou seja, para além dos sistemas modelizantes frequentemente acionados para a organização textual desta dimensão linguageira do processo comunicativo estabelecido por teorias da Administração como as apresentadas neste estudo. Tais noções constituem uma semiotização promovida pelas organizações, que aguarda a tensão produzida subjetivamente pelo processo de tradução.

Ao retomar as categorias analíticas, estrutura dos enunciados e modelizações, a reflexão sobre os valores mobiliza a organização dos dados a partir de quatro outras categorias: 1) mercado (foco no cliente, inovação, obstinados por resultados), 2) relações interpessoais (integridade, respeito), 3) organização/empresa (solidez financeira, austeridade, sustentabilidade, responsabilidade social) e 4) atributos do trabalhador (agilidade, trabalho em equipe, foco, ambição, flexibilidade). Pode-se sugerir que esses quatro subgrupos são orientados por dois polos: A) afetivo/emotivo, próximo à concepção de Bethlem (1998), cujo foco está no sujeito/pessoa, que pode agregar sua carga simbólica à atualização textual no contexto organizacional; B) mercado/negócio, proposta que se aproxima dos pressupostos de Alves (1997) acerca da definição de padrões de comportamento e critérios de escolha. Nesse sentido, percebe-se que as empresas vinculam seus textos aos produzidos pela semiosfera 
organizacional, mediante a tensão entre teorias e suas traduções às conjecturas específicas do sistema modelizante oriundo do segmento ao qual essas varejistas se vinculam.

A síntese entre semelhanças e diferenças é expressa no Quadro 1.

Quadro 1 - Missão, visão e valores: similaridades e diferenças

\begin{tabular}{|c|c|c|}
\hline Categoria & $\begin{array}{c}\text { Similaridades } \\
\end{array}$ & Diferenças \\
\hline Missão & $\begin{array}{c}\text { Tom - Formal, mas coloquial } \\
\text { Forma - enunciados longos } \\
\text { Estrutura - conteúdo: clientes e } \\
\text { objetivos/anseios futuros - foco no } \\
\text { mercado }\end{array}$ & $\begin{array}{c}\text { Forma - apresentação em tópicos } \\
\text { Estrutura - conteúdo: menção a públicos diversos } \\
\text { Associação simbólica "Expressar-se por meio da } \\
\text { moda" }\end{array}$ \\
\hline Visão & $\begin{array}{c}\text { Forma - Frases curtas } \\
\text { Conteúdo - futuro do negócio expressa } \\
\text { de modo preciso } \\
\end{array}$ & $\begin{array}{c}\text { Conteúdo - aciona elementos subjetivos e } \\
\text { ambíguos } \\
\text { Detalhamento de segmento } \\
\end{array}$ \\
\hline Valores & $\begin{array}{c}\text { Estrutura focada em dois planos (afetivo } \\
\text { e mercadológico); } \\
\text { Aciona elementos afetivos } \\
\text { majoritariamente; } \\
\text { Menção às pessoas de modo direto } \\
\text { Forma - tópicos }\end{array}$ & $\begin{array}{c}\text { Uso de frase de efeito; } \\
\text { Oscilação entre os termos acionados/sinônimos }\end{array}$ \\
\hline Síntese & $\begin{array}{l}\text { Textos amplamente modelizados pela } \\
\text { Teoria da Administração Estratégica }\end{array}$ & $\begin{array}{c}\text { Evidência do processo de tradução entre textos } \\
\text { diversos }\end{array}$ \\
\hline
\end{tabular}

Fonte: elaborado pelos autores

A síntese apresentada no Quadro 1 faz perceber que mesmo dentro do campo das similaridades, a diversidade de significados acionados pelos textos é característica dos múltiplos sistemas modelizantes que são postos em interação à produção dos discursos organizacionais. Nesse sentido, o ponto de vista da Semiótica da Cultura auxilia no entendimento da atuação desses sistemas, bem como permite complexificar o processo de gestão nas organizações, a partir dos elementos simbólicos conectados. Embora alguns autores das teorias da Administração, nos âmbitos da Gestão Estratégica e da Cultura Organizacional, produzam seus textos com a intenção de flexibilizar o sistema modelizante que as constituem, toda a carga histórica que envolve esses arcabouços tende a promover uma modelização mais rígida e assentada em pilares específicos em prol da padronização cultural. Como tal movimento é fadado ao fracasso, visto à permanente tensão entre textos diversos, convergir o modo de perceber o mundo, proveniente da escola russa, mostra-se profícuo. 


\section{QUE TEXTO, AFINAL, PODE EMERGIR DESSE ENTRECRUZAR DE FRONTEIRAS?}

Um sinuoso e hermético mapa guia a investigação até esse ponto. Ponto final de uma organização de informações, antes soltas no espaço da semiosfera. Transformada em texto e ancorada no sistema modelizante da escrita científica, é explícito que esta reflexão resulta de um percurso que tem como intenção a imbricação do simbólico às perspectivas simplificadoras no estudo das organizações. Trata-se de um desafio que vem traçando caminhos recentemente. Uma vez cruzadas tais fronteiras, não há mais possibilidade de regresso. Diante disso, considera-se que o estudo, mesmo diante de diversas limitações, encoraja a busca de pontos de vista singulares para o estudo das organizações, como é o caso da Semiótica Russa. Transformar a realidade passa por investir em traduções dos textos postos e produzir novos, mais complexos e adequados aos desafios contemporâneos do convívio entre indivíduos.

Diante das expectativas que orientaram esta produção textual, podem-se apontar diferentes sistemas modelizantes atuantes na elaboração dos textos de missão, de visão e de valores de empresas do ramo varejista, do segmento Moda e Esportes. Embora a articulação teórica tenha se sustentado por aspectos referentes à administração estratégica e à cultura organizacional, a análise dos corpora evidencia a evocação de sistemas orientados pela teoria do marketing, da psicologia e da sociologia, além de estruturas decorrentes da abrangência do negócio das empresas: varejos de vestuário. O segmento Moda também implica a produção desses textos, mesmo que com densidade menos evidente. Com base no pressuposto inicial de que as diferenças estariam relacionadas à missão das empresas e semelhanças acerca da visão e dos valores, confirma-se essa tendência ao longo da análise, o que expressa como tais modelizações estão presentes nas possibilidades de interpretação.

Por fim, sugere-se a elaboração de estudos futuros mediante outros elementos da cultura das organizações, a fim de ratificar ou retificar a nomenclatura da "semiosfera organizacional" instituída neste artigo. Além disso, acredita-se que outras pesquisas possam refinar a inter-relação entre os sistemas modelizantes propostos ou mesmo evidenciar pontos de tradução. Dentre as limitações que são identificadas, e merecem atenção para reflexões futuras, estão a amplitude das informações acionadas e a multiplicidade de sistemas às quais se referem. Nesse sentido, reconhece-se que diversas lacunas tendem a ser reconhecidas pelo leitor. Entretanto, sob a perspectiva da Semiótica da Cultura, tais lacunas são fundamentais para o desenvolvimento de novos textos. 


\section{REFERÊNCIAS}

ALVES, S. Revigorando a Cultura da Empresa. São Paulo: Makron Books, 1997.

BETHLEM, A. Estratégia Empresarial. São Paulo: Altlas, 1998.

BULGACOV, S. Estudos Comparativos e de Caso de Organizações de Estratégias.

Organizações \& Sociedade. V. 5, n. 11, p. 53-76, jan./abr.,1998. Disponível em: <http://www.scielo.br/pdf/osoc/v5n11/01.pdf>. Acesso em: 08 dez. 2016.

C\&A. Disponível em: 〈http://www.cea.com.br/Institucional/Conheca-a-CEA〉. Acesso em 03 jul.2016.

CERTO, S. et al. Administração Estratégica. São Paulo: Pearson Education do Brasil, 2010.

COSTA, E. A. da. Gestão Estratégica da Empresa que Temos para a Empresa que Queremos. São Paulo: Saraiva, 2007.

DRUCKER, P. Sociedade pós-capitalista. São Paulo: Pioneira, 1993.

GIL, A. C. Métodos e Técnicas de Pesquisa Social. São Paulo: Atlas, 2008.

GRUPO AVENIDA. Disponível em: 〈http://www.grupoavenida.com.br/index.php?url=quem_somos〉. Acesso em 03 jul.2016.

GRUPO GUARARAPES. Disponível em:

$<$ http://ri.riachuelo.com.br/guararapes/web/conteudo_pt.asp?idioma=0\&conta=28\&tipo=1988>7. Acesso em 03 jul.2016.

HILAL, A. Dimensões e Clusters de Cultura Organizacional. Rio de Janeiro: MAUAD, 2003.

IBEVAR, Instituto Brasileiro de Executivos do Varejo e do Mercado de Consumo. Ranking Ibevar 2015. Disponível em:

<http://media.wix.com/ugd/71ecd2_7f5b7737be4e4424952b55488f827a30.pdf>. Acesso em: 03 jul. 2016.

LOJAS HAVAN. Disponível em: 〈http://www.lojashavan.com.br/ideologia〉. Acesso em 03 jul.2016.

LOJAS PERNAMBUCANAS. Disponível em:

$<$ https//www.conformidade.com.br/canaleticapemambucanas/images/codigo.pdf> . Acesso em 03 jul. 2016.

LOJAS RENNER. Disponível em:

<http://www.lojasrenner.com.br/institucionaljisessionid=P1xYX5nQk1vVwkmd5HShXp1JPW.JGj6T51FPGGJy kLRb7BGTcqudn!778860621>. Acesso em 03 jul. 2016.

LOTMAN, I. Sobre o problema da tipologia da cultura. In: SCHNAIDERMAN, B. Semiótica Russa. São Paulo: Perspectiva, 1979.

LOTMAN, Y. Extructura del Texto Artístico. Madrid: Arabi, 1982. 
LOTMAN, Y. M. La Semiosfera I: semiótica de la cultura y del texto. Madrid: Ediciones Cátedra, 1996.

LOTMAN, I; USPENSKII, B. Ensaios de Semiótica Soviética. Lisboa: Horizonte, 1981.

MACHADO, I. Escola de Semiótica: a experiência de Tártu-Moscou para o estudo da cultura. São Paulo: Ateliê Editorial, 2003.

MACHADO, I. Cultura como Campo Semiótico. Revista USP, São Paulo, n. 86, p. 157-166, jun./ago., 2010.

PELBART, P. P. Vida Capital: ensaios de biopolítica. São Paulo: Iluminuras, 2003.

SOUZA, I. L.; LEÃO, A. L. M. S. Movimento Sensual: um estudo da narrativa mitológica na publicidade de uma marca de moda praia. Organizações \& Sociedade, Salvador, n. 67, p. 623-649, nov./dez., 2013.

SPINK, M. J. Linguagem e Produção de Sentidos no Cotidiano. [online]. Rio de Janeiro: Centro Edelstein de Pesquisas Sociais, 2010. 72 p. Disponível em:

<http://books.scielo.org/id/w9q43>. Acesso em: 12. ago. 2014. 